\title{
Performance evaluation of atmospheric biomass integrated gasifier combined cycle systems under different strategies for the use of low calorific gases
}

\author{
Monica Rodrigues ${ }^{\mathrm{a}}$, Arnaldo Walter ${ }^{\mathrm{b}, *}$, André Faaij ${ }^{\mathrm{c}}$ \\ a Centro de Desenvolvimento Energético Amazônico-CDEAM, Av. Rodrigo Otávio Jordão Ramos, 3000, Campus Universitário, \\ Coroado I, 69077-000 Manaus, Brazil \\ ${ }^{\mathrm{b}}$ Mechanical Engineering College, State University of Campinas - Unicamp, P.O. Box 6122, 13081-970 Campinas, Brazil \\ ${ }^{\mathrm{c}}$ Department of Science, Technology and Society, Utrecht University, Padualaan 14, 3584 CH Utrecht, The Netherlands
}

Received 10 March 2006; accepted 27 September 2006

Available online 4 December 2006

\begin{abstract}
This work aims at a performance evaluation of atmospheric BIGCC (biomass integrated gasifier combined cycle) systems operating under different strategies for the use of low calorific fuel in gas turbines. The fuel is a synthetic gas derived from gasification of sugar cane residues. Two analysed strategies for surge control on gas turbines originally designed for operation on natural gas are de-rating and air extraction from the compressor. Another strategy for use of biomass derived gas is the retrofit of a gas turbine through modification of the expander geometry. Three generic gas turbines, whose main parameters have been taken from off the shelf machines, are proposed as representative of certain classes of gas turbines. Results are compared to the hypothetical situation in which it is possible to accept any increase in gas turbine pressure ratio. According to the results, de-rating is the worst surge control strategy, both from the point of view of power production and thermal efficiency. Conversely, results showed considerable gains that can be obtained on cycle power production when the gas turbine expander is modified. Additionally, an overview of issues concerning the suitability of sugar cane residues (bagasse and trash) for the production of gasified gas and its use in BIGCC plants is presented.
\end{abstract}

(C) 2006 Elsevier Ltd. All rights reserved.

Keywords: BIGGT technology; Sugar cane residues; Low calorific gas; Gas turbine off design

\section{Introduction}

Currently, most biomass electricity generation is based on steam cycles. These plants are usually small capacity $\left(20-50 \mathrm{MW}_{\mathrm{e}}\right)$ and present relatively low electric efficiency $(\approx 20 \%)$ [1]. Conversely, the biomass integrated gasifier gas turbine/combined cycle (BIGGT/CC) technology, which is still in development, is expected to achieve efficiencies around $40 \%$ for atmospheric gasification of wood at modest scales [2,3], but further improvements are necessary for it to become competitive. Cost reduction seems espe-

\footnotetext{
* Corresponding author. Tel.: +55 193788 3283; fax: +55 1932893722 E-mail address: awalter@fem.unicamp.br (A. Walter).
}

cially possible by improving the conversion efficiency [2], which could be achieved using existing larger natural gas combined cycles with efficiencies over $50-55 \%$ electric.

Following the pioneer demonstration cogeneration plant $\left(6 \mathrm{MW}_{\mathrm{e}}\right.$ and $\left.9 \mathrm{MW}_{\text {th }}\right)$ built in Värmano (Sweden) [4], an $8 \mathrm{MW}_{\mathrm{e}}$ atmospheric BIGCC unit was built in UK (the ARBRE - ARable Biomass Renewable Energy plant). In 2002, the gas turbine was fed with biomass derived gas (BDG) during a short period of time. The project was ended in the same year, apparently due to a contractual dispute and not due to technological problems [5]. The atmospheric biomass gasifier that is proposed for this work has been previously demonstrated in Italy in two units of $15 \mathrm{MW}_{\text {th }}$ processing refuse derived fuel 


\section{Nomenclature}

$A^{*} \quad$ critical area $\left(\mathrm{m}^{2}\right)$

BDG biomass derived gas

BIGGT/CC biomass integrated gasifier gas turbine/ combined cycle

CFB circulating fluidised bed

CMV compressor map variable

HRSG heat recovery steam generator

IGCC integrated gasifier combined cycles

IGV inlet guide vanes

LCV low calorific value

$m$ mass gas flow $(\mathrm{kg} / \mathrm{s})$

$\begin{array}{ll}p & \text { total pressure }(\mathrm{kPa}) \\ \text { ppbw } & \text { parts per billion weight } \\ \text { ppm } & \text { parts per million } \\ \mathrm{PR} & \text { compressor pressure ratio } \\ R & \text { universal gas constant }(\mathrm{kJ} / \mathrm{kmol} \mathrm{K}) \\ \mathrm{RDF} & \text { refuse derived fuel } \\ \mathrm{RMF} & \text { reduced mass flow } \\ T & \text { gas temperature }(\mathrm{K}) \\ & \\ \text { Greek } & \\ \gamma & \text { ratio between specific heats }\end{array}$

to be able to accommodate a larger mass flow and operate on the design condition because of its expander with a modified geometry (i.e. increasing the blade height or nozzle discharge angle).

This paper assesses the impact of different strategies for BDG use on the performance of BIGCC power cycles. This work is part of a broader research that aims at investigating co-firing (burning a mix of natural gas and biomass derived gas) as a mechanism to improve short term BIGCC cost-effectiveness $[9,10]$.

The biomass considered within this study is sugar cane bagasse and sugar cane trash (leaves and points of the plant). Bagasse is a residue of the sugar cane crushing process and is relatively cheap. Trash is becoming increasingly available in Brazil due to the increasing implementation of green cane harvesting.

\section{Issues on suitability of sugar cane residues for BIGG technology}

Physical and chemical properties of the biomass affect the suitability of BDG for BIGCC technology. Physical properties, such as size and density, affect the handling and feeding systems. Chemical properties, such as composition, heating value and ash content, have a strong impact on gasification and cleanup systems. There are limitations on experimental data for sugar cane residues and, more importantly, the cleaning of BDG has not been demonstrated commercially so far. Hence, the assessment was performed by comparison with other biomass feedstock that has been evaluated in the literature.

\subsection{Physical properties}

Typical values of some physical characteristics of sugar cane bagasse and trash are presented in Table 1. A biomass particle size $\leqslant 5 \mathrm{~cm}$ allows for high efficiency conversion in fluidised-beds due to better mixing with the bed material and greater carbon conversion rates [11]. The size of sugar design conditions. The redesigned gas turbine is considered 
Table 1

Physical characteristics of sugar cane bagasse and trash

\begin{tabular}{lll}
\hline & Chopped trash & Bagasse \\
\hline Particle size & $<1-10 \mathrm{~cm}^{\mathrm{a}}$ & $<5 \mathrm{~cm}^{\mathrm{b}}$ \\
Bulk density $\left(\mathrm{kg} \mathrm{m}^{-3} \mathrm{db}\right)$ & $95-130^{\mathrm{c}}$ & $50-75^{\mathrm{c}}$ \\
Moisture content $(\mathrm{wt} \%$ wet $)$ & $30^{\mathrm{d}}$ & $50^{\mathrm{b}}$ \\
\hline
\end{tabular}

${ }^{\text {a }}$ Chopped-leaves size obtained using a chaff cutter [12]

${ }^{\mathrm{b}}$ Bagasse available from sugar factories almost powdery [12].

${ }^{\mathrm{c}}$ For loose leaves [12].

${ }^{\mathrm{d}}$ Copersucar [13].

cane trash particles depends on the machine used to shred them. Data presented in Table 1 correspond to the use of a chaff cutter [12]. An advantage of bagasse is its small particle size, frequently smaller than $5 \mathrm{~cm}$, resulting from the crushing process in sugar factories.

The moisture content of biomass greatly affects the amount of energy used for drying and the BDG composition. Because the crushing process involves watering, bagasse available at sugar cane mills has a higher moisture content than trash; the moisture content of bagasse is around $50 \%$. The tops and leaves of sugar cane plants, when left on the field, have $35 \%$ moisture content.

Furthermore, the low bulk density and cohesive characteristics of bagasse and cane trash can cause an accumulation of the fuel in the feeding system, creating difficulties for the flow into the gasifier.

\subsection{Chemical properties}

Typical results of ultimate analysis of sugar cane bagasse and sugar cane trash are presented in Table 2. The chemical composition of the biomass feedstock has a strong influence on the design of the cleanup gas section that is an essential part of the BIGCC system. Some inorganic elements present in the feedstock can cause corrosion in the equipment downstream, and some are pollutants. Gas turbines, for instance, have very strict limits for particulates and alkali metals in the fuels delivered to the combustor in order to prevent erosion, fouling and corrosion of the gas turbine hot section [14].

Table 2

Ultimate analysis of sugar cane bagasse and trash

\begin{tabular}{lcc}
\hline Wt $\%-$ dry basis & Bagasse $^{\mathrm{a}}$ & Trash $^{\mathrm{b}}$ \\
\hline $\mathrm{C}$ & 46.3 & 45.0 \\
$\mathrm{O}$ & 43.3 & 44.0 \\
$\mathrm{H}$ & 6.4 & 6.0 \\
$\mathrm{~N}$ & - & - \\
$\mathrm{S}$ & - & - \\
$\mathrm{Cl}$ & - & - \\
Ash & 4.0 & 5.0 \\
LHV $(\mathrm{MJ} / \mathrm{kg})$ & 17.5 & 17.6 \\
\hline
\end{tabular}

\footnotetext{
${ }^{a}$ Walter et al. [15].

b COPERSUCAR [17].
}

Another matter of concern is the fuel bound nitrogen that may be a significant source of $\mathrm{NO}_{x}$ emissions when $\mathrm{BDG}$ is used in gas turbines. Chlorine and sulphur are also potential contaminants. Sulphur content can be quite high in trash originating from plantations fertilized with vinasse $^{1}[16]$. These components can be effectively removed by the scrubber [3].

\subsection{Contaminants and cleaning considerations}

The composition of the bagasse and trash derived raw gas and its contaminant contents are not available in the literature. The Swedish company TPS (Thermiska Processer $\mathrm{AB}$ ) and the Brazilian COPERSUCAR performed gasification tests in an atmospheric air blown gasifier similar to that considered in this paper. It is known that the results were positive, as stated by Waldheim et al. [17]. A discussion of the main contaminants on the basis of available experience with other biomass fuels is presented below.

\subsubsection{Tars}

Tars are heavy condensable organic compounds formed during gasification of biomass. They account for $0.5-1.5 \%$ by mass of the product from a typical bed-bed gasifier, depending on the temperature. If tars condense on cool surfaces of the cleanup section, severe operating problems can result, including constricted piping or clogged valves and filters [11]. There are several uncertainties regarding the maximum allowable tar levels for gas turbines, as manufactures do not list tar in their standards (i.e., maximum allowance).

Tars often constitute such an important energy component of the fuel gas that removing them from the gas would result in a loss of system efficiency. According to TPS technology, the circulating fluidised bed is followed by a reactor in which tar is broken into smaller hydrocarbon molecules that are lighter and stable (see Section 2.4). This tar cracking technology uses dolomite as a catalyst and additional air is provided to the catalytic cracker to maintain an elevated temperature. This second reactor leads to the production of gas with very low levels of tar, so that wet scrubbing can be used to remove the remaining contents [18]. It is generally understood that there will be virtually no tars in the gas that enters the combustion chamber.

\subsubsection{Particulates}

Particulates, even in small quantities, can cause turbine erosion [18]. According to Kloster et al. [19] for gas turbines, the required gas quality regarding particles smaller than $5 \mu \mathrm{m}$ is $30 \mathrm{mg} / \mathrm{Nm}^{3}$. Fuel gas from biomass contains very small carbonaceous particles, which are difficult to

\footnotetext{
${ }^{1}$ Vinasse is an industry by product applied as a sugar cane plantation fertiliser.
} 
be removed by cyclones. The suggested cleaning device for BIGCC systems based on atmospheric gasification is a baghouse filter, followed by a scrubber that would help remove even very fine particles [2].

\subsubsection{Alkalis}

Alkali metals, such as sodium and particularly potassium, naturally exist in biomass. Part of these alkalis vaporize depending on the content in the fuel and on the gasification conditions. Alkali metals can cause high temperature corrosion of turbine blades, stripping off their protection layer, and should not exceed certain limits at the entry of the gas turbine. For the LM2500 turbine, the maximum permissible concentration of contaminants in the flue gas stream of alkalis $(\mathrm{Na}+\mathrm{K}+\mathrm{Li})$ is 4 ppbw (parts per billion weight) with operation on natural gas [2]. Considering the dilution when low calorific gases are used, the maximum allowable concentration goes up to 20 ppbw. The limits for industrial gas turbines are $0.1 \mathrm{ppm}$ [18]. Salo and Mojtahedi [20] conducted tests with a $15 \mathrm{MW}_{\text {th }}$ pressurized fluidised bed gasification test rig in Finland for various biomass sources, including willow, wood and straw, reducing alkali levels to less than $0.1 \mathrm{ppm}$. The results from Salo and Mojtahedi [20] aim at hot gas cleanup in which no scrubber is used, and the BDG is cooled to $350-400{ }^{\circ} \mathrm{C}$. For the configuration considered at this work, the BDG goes through the scrubber in which it is cooled to a temperature between 35 and $40{ }^{\circ} \mathrm{C}$, so that removal of the alkalis is expected to be complete $[2,3]$. Anyhow, as shown in Table 3, the content of potassium in the ash composition of sugar cane trash is lower than in the wheat straw analysed by Salo and Mojtahedi [20].

For sugar cane bagasse, alkalis levels will be even lower as a result of the watering during the process of crushing the sugar cane that helps to remove these soluble contaminants. In fact, spraying or soaking biomass in water is a pre-treatment can substantially reduce the alkalis content in the biomass [21].

Table 3

Ash composition of various biomass sources

\begin{tabular}{lccc}
\hline Oxide $(\%$ ash $)$ & Bagasse $^{\mathrm{a}}$ & Trash $^{\mathrm{a}}$ & Wheat straw $^{\mathrm{b}}$ \\
\hline $\mathrm{SiO}_{3}$ & 46.61 & 58.00 & 35.84 \\
$\mathrm{Al}_{2} \mathrm{O}_{3}$ & 17.69 & - & 2.46 \\
$\mathrm{TiO}_{2}$ & 2.63 & - & 0.15 \\
$\mathrm{Fe}_{2} \mathrm{O}_{3}$ & 14.14 & 2.00 & 0.97 \\
$\mathrm{CaO}$ & 4.47 & 13.00 & 4.66 \\
$\mathrm{MgO}$ & 3.33 & 4.30 & 2.51 \\
$\mathrm{Na}$ & $\mathrm{O}$ & 0.30 & 10.50 \\
$\mathrm{~K}_{2} \mathrm{O}$ & 0.79 & 13.40 & 18.40 \\
$\mathrm{SO}_{3}$ & 4.15 & 7.31 & 5.46 \\
$\mathrm{P}_{2} \mathrm{O}_{5}$ & 2.08 & 2.30 & 1.47 \\
Undetermined & 2.72 & 1.64 & 17.58
\end{tabular}

${ }^{\text {a }}$ COPERSUCAR [16].

b Salo and Mojtahedi [20].

\subsubsection{Nitrogen oxides - fuel bound nitrogen (FBN)}

Simulation and experiments conducted in Hawaii [22] have demonstrated that FBN from biomass is mostly partitioned in $\mathrm{NH}_{3}$ and $\mathrm{N}_{2}$ during gasification. Ammonia will then cause most of the emissions of fuel bound $\mathrm{NO}_{x}$ during the combustion of syngas in the gas turbine. Lietti et al. [23] have investigated the oxidation of $\mathrm{NH}_{3}$ and $\mathrm{NO}_{x}$ formation during catalytic combustion. The combustion experiments led to the formation of significant amounts of $\mathrm{NO}_{x}$, particularly $\mathrm{NO}$ from the ammonia $(0.3 \mathrm{~mol} \%)$ content in the gas, in contrast with the low $\mathrm{NO}_{x}$ emission requirements of gas turbine applications.

According to Consonni and Larson [3], the wet scrubbing step following the gasifier can also remove ammonia in the BDG; thereby essentially eliminating fuel bound $\mathrm{NO}_{x}$. The downside of the cleaning with a scrubber is the need for a wastewater treatment. The demonstration of gas cleanup for atmospheric systems is yet to be pursued, but there is very little uncertainty as to the cleaning effectiveness of such systems [3].

\subsubsection{Nitrogen oxides - thermal nitrogen}

The decisive factor affecting the formation of thermal $\mathrm{NO}_{x}$ is the flame temperature, which varies exponentially with this parameter [5]. Because of its high temperature, thermal nitrogen is a matter of concern when natural gas is used. Cook et al. [24] performed experiments on the combustion of low calorific gases and found that $\mathrm{NO}_{x}$ emissions could be correlated as a simple function of the stoichiometric flame temperature for a wide range of heating values. In general, the flame temperatures of low calorific gases are typically $500-1000 \mathrm{~K}$ lower than those of natural gas or distillate oils, so thermal $\mathrm{NO}_{x}$ is not expected to be a problem in BIGCC systems [25].

\subsection{Fuel gas composition}

Modelling the complex chemical kinetics that occur in the gasifier is beyond the scope of this work. Here, the raw BDG composition obtained from gasification of sugar cane residues was predicted based on a model developed with the ASPEN Plus ${ }^{\odot}$ simulator. First, the results of this model for the gasification of typical wood have been compared with data presented by Consonni and Larson [3] for the same biomass. This reference of comparison was chosen due to the accuracy of the results to the gas composition provided by the technology developers. Results obtained from the model and the compositions for comparison are presented in Table 4.

Sequentially, in order to estimate the BDG composition from sugar cane residues, the same model was applied. As the ultimate analysis of bagasse and trash are quite similar, the composition for the raw BDG was considered to be the same for both biomasses. Clean BDG composition was predicted considering that all contaminants are removed during the cleanup process and that most of the water condenses, so that the water remaining in the syngas at the exit 
Table 4

Estimated raw BDG composition and composition of reference (mol\%) wood

\begin{tabular}{lcc}
\hline & Estimated composition & Reference $^{\mathrm{a}}$ \\
\hline $\mathrm{H}_{2}$ & 15.0 & 14.8 \\
$\mathrm{CO}$ & 18.0 & 19.8 \\
$\mathrm{CO}_{2}$ & 9.5 & 10.4 \\
$\mathrm{CH}_{4}$ & 2.4 & 2.6 \\
$\mathrm{C}_{2} \mathrm{H}_{2}$ & - & 0.9 \\
$\mathrm{C}_{6} \mathrm{H}_{6}$ & 0.6 & - \\
$\mathrm{H}_{2} \mathrm{O}$ & 11.8 & 11.6 \\
$\mathrm{~N}_{2}$ & 42.1 & 39.1 \\
$\mathrm{Ar}$ & - & 0.5 \\
$\mathrm{H}_{2} \mathrm{~S}$ & 0.1 & - \\
$\mathrm{NH}_{3}$ & 0.3 & - \\
Tars & 0.2 & 0.3 \\
\hline
\end{tabular}

${ }^{a}$ Consonni and Larson [3].

Table 5

Estimated raw and clean BDG composition ( $\mathrm{mol}^{\%} \%$ ) - sugar cane residues

\begin{tabular}{lcc}
\hline & Raw BDG & Clean BDG \\
\hline $\mathrm{H}_{2}$ & 14.99 & 16.69 \\
$\mathrm{CO}$ & 17.95 & 19.98 \\
$\mathrm{CO}_{2}$ & 9.42 & 10.49 \\
$\mathrm{CH}_{4}$ & 2.36 & 2.63 \\
$\mathrm{C}_{6} \mathrm{H}_{6}$ & 0.30 & 0.33 \\
$\mathrm{H}_{2} \mathrm{O}$ & 11.75 & 3.24 \\
$\mathrm{~N}_{2}$ & 41.90 & 46.64 \\
Contaminants & 1.33 & - \\
\hline
\end{tabular}

of the scrubber is saturated at that temperature. Table 5 presents the estimated raw and clean syngas compositions.

\section{Gas turbine operation with low calorific fuel}

\subsection{Required modifications on gas turbines}

Natural gas and light oil distillates are the preferred fuels for gas turbines, but many other fuels have been used successfully, including low calorific value (LCV) gases such as gases from iron and steel industries with heat content as low as $3 \mathrm{MJ} / \mathrm{m}^{3}$ [3]. Some modifications should be necessary for the use of LCV fuels in a gas turbine originally designed to use natural gas as fuel. These modifications comprise gas turbine layout for the changed mass flow, fuel delivery/injection system, fuel nozzles and fuel manifold and combustion chamber [26]. To burn LCV fuels, the can type combustors used in many industrial gas turbines generally provide adequate cross section and volume for complete and stable combustion with acceptable pressure drops [3]. According to De Kant et al. [27], whose work is based on a survey of manufacturers for the use of $\mathrm{BDG}$, replacement of the combustion chamber is necessary for use of BDG in a conventional combustion chamber with water or steam injection.

There has been no commercial operating experience with LCV fuels in aero-derivative gas turbines that utilize more compact combustors, but the GE LM2500 has been modified for operation with BDG $[3,26]$. In this case, it is proposed that the expander of the steam injection model is used in order to accommodate better the larger gas flow together with the fuel injection system modifications as suggested in Ref. [26].

The issue of combustion stability is closely related to the low heating content of the BDG. A combined cycle power plant built in a steel mill in Taranto, Italy, had the combustion system of its gas turbines modified to operate on a gas mixture with a LHV as low as $6 \mathrm{MJ} / \mathrm{Nm}^{3}$ [28]. The LHV of BDG ranges between 5 and $6 \mathrm{MJ} / \mathrm{Nm}^{3}$ for directly heated gasifiers [3]. General Electric performed the combustion of a gas derived from air blown atmospheric gasification having a heating value of $3.7 \mathrm{MJ} / \mathrm{Nm}^{3}$ [8]. Experiments performed with a modified combustor can of a Typhoon gas turbine at Delft Technical University, The Netherlands, have achieved stable combustion of BDG with heating value as low as $2.5-3 \mathrm{MJ} / \mathrm{Nm}^{3}$ [25]. The BDG from sugar cane residues considered in this work has a heating value close to $6 \mathrm{MJ} / \mathrm{Nm}^{3}$, so no flame stability problems related to heat content should be expected, provided the gas has a minimum hydrogen content.

The hydrogen content of BDG is another important issue for BIGCC systems. Hydrogen has a much higher flame propagation speed than $\mathrm{CO}$ or $\mathrm{CH}_{4}$, the main other combustible components in BDG, thereby favouring flame stability. On the other hand, higher hydrogen content increases the risk of back stream flame propagation for the case of dry low $\mathrm{NO}_{x}$ combustion chambers [27]. General Electric specifications for its dry-low $\mathrm{NO}_{x}$ combustion systems allow no hydrogen in the fuel due to the design of the combustion can. ABB has limited the hydrogen content to $5 \%$ (per volume) for its dry-low $\mathrm{NO}_{x}$ systems. As presented in Table 5, the predicted hydrogen content for the BDG considered in this work is much higher than such limit. The use of water/steam injection as alternative for $\mathrm{NO}_{x}$ control is assumed for this work. This assumption doesn't reflect the trend because more and more gas turbines are being equipped with dry-low $\mathrm{NO}_{x}$ combustors directly at the factory. If the dry-low $\mathrm{NO}_{x}$ concept is to be considered, the developers should limit the amount of fuel gas, so the hydrogen content in the mixture would not reach the limit for hydrogen content as defined by the manufacturers.

\subsection{Strategies for the use of LCV fuels in gas turbines}

Taking into account that the gas turbines were designed for operation on natural gas, the increase in mass flow due to the use of LCV fuels can only be accomplished through an increase on gas pressure and/or a decrease in gas temperature at the inlet of the gas turbine expander. The increase in compressor pressure ratio is, however, limited to a value that keeps a safe margin from the surge line. As previously mentioned, another option is the redesign of the gas turbine expander, changing its geometry. 
De-rating the gas turbine by imposing a lower burning temperature, consequently reducing the pressure ratio to acceptable levels, is the simplest surge control strategy for the use of BDG in gas turbines that have been designed for natural gas $[3,29]$. De-rating will also lead to lower thermal and mechanical stresses on airfoils that could increase otherwise [30]. Thus, de-rating increases the reliability of the gas turbine, which might be important in demonstration projects. The downside is that the gas turbine firing temperature governs the cycle efficiency, and thus, there is a strong penalty for the overall cycle efficiency. Moreover, the performance of the downstream steam cycle is also reduced due to the lowering of the parameters of the steam produced at the HRSG (i.e. temperature, pressure and flow) [31].

Another surge control strategy is bleeding air from the compressor to reduce the mass flow at the expander entrance. This is an option already used for surge control of gas turbines, even when natural gas is burned [8], but the continuous extraction of air to allow the use of LCV fuels should require some retrofit [32]. Bleeding air from the compressor has been investigated for IGCC (integrated gasifier combined cycles) systems $[30,32,33]$ when the air separation plant is located on site with the gas turbine units. The waste nitrogen from the air separation plant is recompressed for return to the gas turbine combustor [30]. The main advantage of this strategy is that the cycle maximum temperature is maintained. The disadvantage is that pressurized air is either lost or used less efficiently in case an expander is installed to make use of it. ${ }^{2}$ In this paper, to facilitate modelling, air is considered to be bled from the compressor outlet. For both control strategies (bleeding and de-rating), some increase of compressor pressure ratio is allowed.

When no surge control strategy is applied, the pressure will rise and eventually can breach the surge margin for the compressor of some gas turbines [27]. Only the manufacturer can determine the actual limit for the pressure increase, so this case is presented here only to illustrate the gains that could be obtained in case the gas turbine could operate beyond the limits defined in this work. Thus, this is not a proposed strategy for the use of BDG. The main advantage of this case is that it will incur higher power production for the gas turbine. The disadvantages are the problems concerned with the increase of shaft torque and thermal loads on airfoils that make this option very aggressive on the equipment [7].

Modifying the geometry of the expander by increasing the blade height or nozzle discharge angle is another strategy for the use of low calorific gases [3]. While this option allows the components to operate in the on design mode, it is definitely the most costly approach, and it could make the operation on natural gas more difficult [7]. Therefore,

\footnotetext{
${ }^{2}$ Expander would have much less efficiency than gas turbine expander and the power produced will be less than that used for compression.
}

it is an option envisioning a market development in the long term. In this paper, the change in geometry is modelled through the increase on critical area in the chock relation (see Section 4.3 for modelling details). The advantages and disadvantages of the gas turbine control strategies are summarized in Table 6 .

\section{Power system description and modelling procedure}

\subsection{Power system description}

The power plant considered here is based on biomass gasification that occurs in an atmospheric air blown gasifier similar to those developed by TPS. This type of gasifier is technically proven, and some units have operated for some time. It is considered that before the gasifier, the biomass moisture content should be reduced to $15 \%$ by using flue gas from the HRSG and that the drying design conditions require a minimum flue gas temperature $\left(200^{\circ} \mathrm{C}\right)$. Gasification occurs within a circulating fluidised bed (CFB) device with air injection at 1-2 bar, and the produced gas leaves the gasifier with a temperature around $900{ }^{\circ} \mathrm{C}$ [19]. A second CFB reactor - the tar cracker - follows the gasifier. This reactor operates at a slightly higher temperature and cracks the tar into lighter hydrocarbons. After the tar cracker, the raw syngas is cooled, and the heat is sequentially recovered to boost steam generation, to preheat the air fed to the gasifier, to preheat the BDG itself (before it enters the gas turbine) and to preheat the feed water for the boiler. After cooling, a baghouse filter removes the particulates and remaining components such as ammonia, while alkali metals and the remaining tars are removed in a wet scrubber.

The gas turbine exhaust gases are led to a HRSG. It was assumed that for all three combined cycles considered in this work, steam is raised in just one pressure level. It is well known that in conventional medium to large combined cycles, thermal efficiencies are increased with steam production in two or three pressure levels. Medium pressure steam re-heating is also common in those cycles. The hypothesis of a single pressure HRSG was assumed because the exhaust must be at high temperature (around $200{ }^{\circ} \mathrm{C}$ ) for biomass drying. The need for drying leads to only marginal gains with multiple pressures in BIGCC cycles [3]. Fig. 1 shows a schematic drawing of the cycle. The light grey line represents the option of bleeding air from the gas turbine compressor, which happens only when the bleeding air strategy is considered.

\subsection{Analysed gas turbines}

The impact of gas turbine control strategies on the performance of BIGCC cycles is investigated for three systems of different capacities. The smallest cycle is based on a gas turbine that is representative of aero-derivative engines. The so called medium and large cycles are based on typical heavy frame gas turbines. Some characteristics of three 
Table 6

Strategies for use of LCV fuels in gas turbines

\begin{tabular}{|c|c|c|c|}
\hline Strategies & Description & Advantages & Disadvantages \\
\hline $\begin{array}{l}\text { Accepting the } \\
\text { increase on } \\
\text { pressure ratio }\end{array}$ & $\begin{array}{l}\text { The compressor is operated at a } \\
\text { higher pressure ratio that leads to a } \\
\text { small reduction on air mass flow }\end{array}$ & $\begin{array}{l}\text { Excluding GT retrofitting this is the option } \\
\text { that leads to maximum power and efficiency } \\
\text { when an atmospheric gasifier is used }\end{array}$ & $\begin{array}{l}\text { Most technically aggressive option due to } \\
\text { increased thermal loads and torque } \\
\text { transmitted }\end{array}$ \\
\hline De-rating & $\begin{array}{l}\text { Reduction of gas turbine firing } \\
\text { temperature }\end{array}$ & $\begin{array}{l}\text { The simplest strategy as it incurs in no } \\
\text { retrofitting; increased reliability }\end{array}$ & $\begin{array}{l}\text { Severe penalties for GT efficiency and } \\
\text { power production }\end{array}$ \\
\hline $\begin{array}{l}\text { Compressor } \\
\text { bleed }\end{array}$ & $\begin{array}{l}\text { Air bled from the compressor } \\
\text { discharge }\end{array}$ & $\begin{array}{l}\text { Small effect on power production. Allows } \\
\text { further return to natural gas }\end{array}$ & $\begin{array}{l}\text { Conversion might affect the proper } \\
\text { distribution of hot air to the combustors } \\
\text { and cause frictional loss in the flow region }\end{array}$ \\
\hline $\begin{array}{l}\text { Expander inlet } \\
\text { nozzle } \\
\text { redesign }\end{array}$ & $\begin{array}{l}\text { Hardware modifications to the } \\
\text { expander inlet nozzle }\end{array}$ & Leads to the best GT performance & $\begin{array}{l}\text { It is a permanent modification making the } \\
\text { use of natural gas more difficult. Is the } \\
\text { most expensive approach }\end{array}$ \\
\hline
\end{tabular}

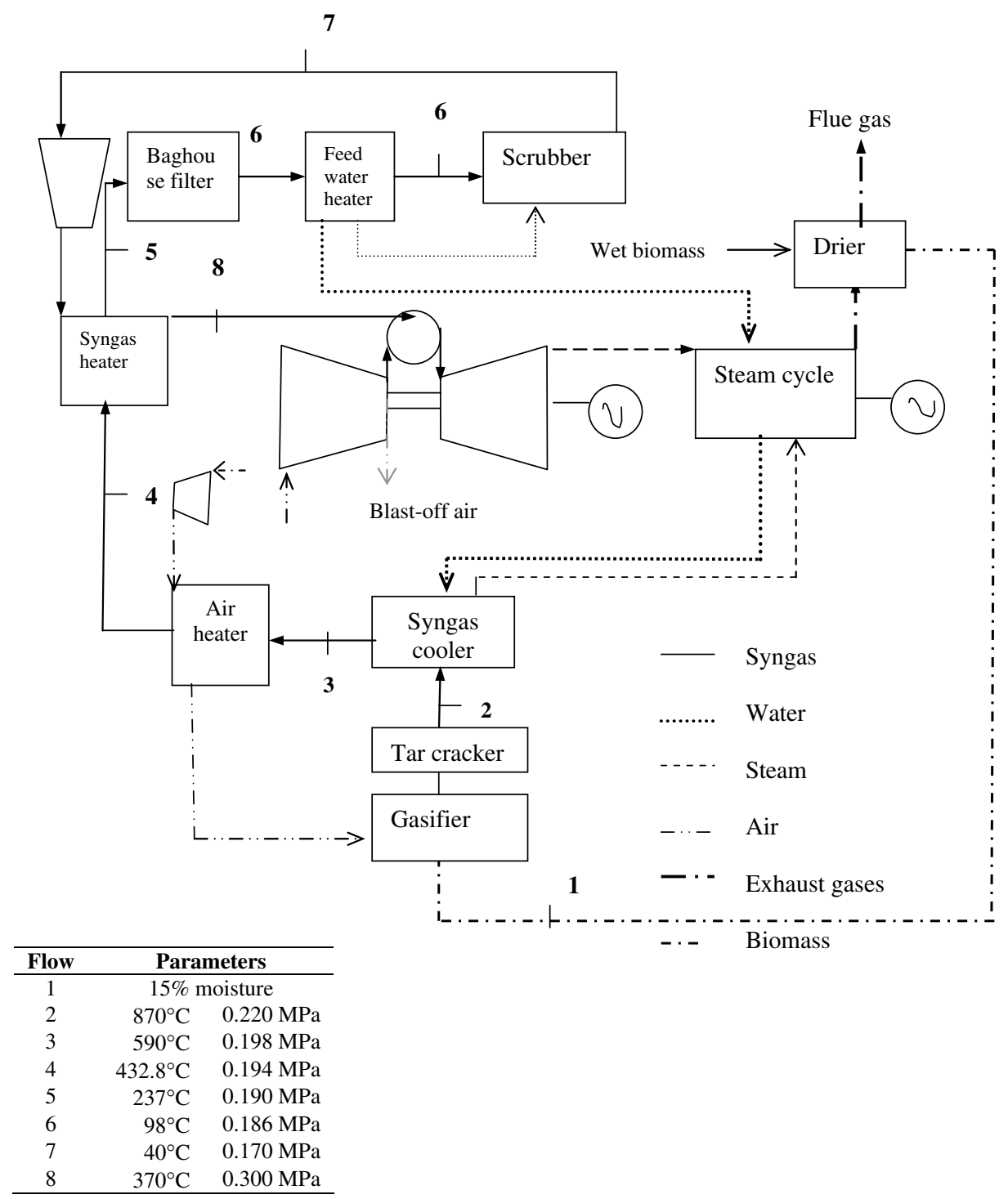

Fig. 1. Scheme of the BIGCC cycle considered and parameters at selected points.

commercial General Electric gas turbines were used for cycle modelling in each case: LM2500, PG6101 (FA) (Frame 6) and PG7001 (Frame 7). LM2500 was chosen for the range of plants of smaller capacities because, as previously mentioned, it has already been adapted for BIGCC units and, secondly, because aero-derivative machines have 
higher efficiency than industrial gas turbines up to $50 \mathrm{MW}_{\mathrm{e}}$. Moreover, the LM2500 that has been modified for the use of biomass has an expander with enlarged area, as it derives from the version with steam augmentation of that turbine class. However, there is still the need for pressure rise control. GE PG6101 produces about $70 \mathrm{MW}_{\mathrm{e}}$ at ISO basis, and its design allows the use of LCV fuels. Moreover, its pressure ratio is adequate for combined cycles, and it was here considered as representative of machines with moderate turbine inlet temperature. On the other hand, for the cycle of largest capacity, a gas turbine was chosen with an inlet temperature close to the maximum a commercial turbine can operate (about $1400^{\circ} \mathrm{C}$ ) [2] and a pressure ratio that is suitable for combined cycles (around 15). The parameters of the three gas turbines considered in the modelling are presented in Table 7.

Parameters not available in the open literature have been estimated during the tuning up. Additional parameters that were considered in the modelling are listed in Table 8 .

\subsection{Modelling details}

Predicting gas turbine performance when LCV fuel is burned requires a procedure for off design modelling. An essential feature of a gas turbine off design procedure is its ability in evaluating actual new compressor pressure ratios. The mass flow relation for choked flow of an ideal gas applied at the inlet of the expander, Eq. (1), allows the calculation of the new compressor pressure ratio:

$m=p \cdot A^{*} \frac{C}{\sqrt{T}}$

where $m$ is the mass flow, $p$ is the total pressure, $A^{*}$ is the critical area and $T$ is the gas temperature. All gas properties are estimated at the expander entrance. The parameter $C$ is given by

$C=\sqrt{\frac{\mathrm{Mol} \cdot \gamma}{R}\left(\frac{2}{\gamma+1}\right)^{\gamma+1 / \gamma-1}}$

where $\mathrm{Mol}$ is the gas molecular weight, $R$ is the universal gas constant and $\gamma$ is the ratio of the specific heats of the gas. The procedure imposes that Eq. (1) should be first applied to estimate the critical area based on the reference
ISO case in which natural gas is burned. The estimated value is then further used as a constant.

Depending on the adopted strategy for the use of LCV fuels (see Section 3.2), the parameters to be changed in Eq. (1) are the gas mass flow, the gas temperature or even the critical area.

The difficulty in predicting gas turbine performance at off design conditions comes from the fact that actual compressor maps are not available in the open literature, and thus, the actual relation between compressor pressure ratio and air mass flow cannot be easily defined. In this work, a generic compressor map, as the one presented in Fig. 2, is assumed for the calculations. The procedure simply establishes, for a given running line, a polynomial function relating the compressor reduced mass flow and the pressure ratio. The reduced mass flow (RMF) is defined by Eq. 3, with all parameters being evaluated at the entrance of the compressor. Thus, for a given pressure ratio (e.g. for the gas turbine operation with $\mathrm{BDG}$ ), it is possible to calculate the corrected air flow:

$\mathrm{RMF}=\frac{m \sqrt{T}}{p}$

For modelling purposes, it is assumed that the compressor always operates over the same running line for both natural gas and BDG. For industrial gas turbines, the limit of pressure ratio for continuous operation is estimated based on the following procedure. It is known that for design values, the running line of the compressor corresponds to a compressor map variable (CMV) between 0.7 and 0.8 . In this paper, it is assumed that the operation with natural gas in the on design mode corresponds to a CMV equal to 0.8. CMV is defined by Eq. (4) and indicates how far compressor operation is from the surge limit $(\mathrm{CMV}=1)$.

$\mathrm{CMV}=\frac{\mathrm{PR}-1}{\mathrm{PR}_{\mathrm{s}}-1}$

where $\mathrm{PR}$ is the compressor pressure ratio and $\mathrm{PR}_{\mathrm{s}}$ is the estimated pressure ratio that corresponds to the surge limit for a given running line.

It was assumed that the limit for continuous operation of industrial gas turbines corresponds to $\mathrm{CMV}=0.88$, and thus, the limit for continuous operation of industrial gas turbines corresponds to pressure ratios 16.2 and 16.3 for the large and medium size units, respectively. For the

Table 7

Main parameters of considered gas turbines operating with natural gas at ISO basis

\begin{tabular}{lllllrr}
\hline Gas turbine & $\begin{array}{l}\text { Air flow rate } \\
(\mathrm{kg} / \mathrm{s})\end{array}$ & $\begin{array}{l}\text { Turbine inlet temperature } \\
(\mathrm{TIT})\left({ }^{\circ} \mathrm{C}\right)\end{array}$ & $\begin{array}{l}\text { Compressor pressure } \\
\text { ratio }\end{array}$ & $\begin{array}{l}\text { Fuel flow } \\
(\mathrm{kg} / \mathrm{s})\end{array}$ & $\begin{array}{l}\text { Exhausting } \\
\text { temperature }\left({ }^{\circ} \mathrm{C}\right)\end{array}$ & $\begin{array}{l}\text { Power } \\
(\mathrm{MW})\end{array}$ \\
\hline Aero-derivative & 68.2 & 1258 & 18.9 & 1.3 & 529 & 21.9 \\
Medium size & 192.3 & 1288 & 14.9 & 4.3 & 597 & 58.1 \\
Large size & 409.8 & 1371 & 14.8 & 9.2 & 583 & 159.0 \\
\hline
\end{tabular}

Source: Gas Turbine World [35]. 
Table 8

Main estimated gas turbine parameters for operation at ISO basis

\begin{tabular}{lllllll}
\hline Gas turbines & \multicolumn{2}{l}{ Isentropic efficiency } & Mechanical efficiency & Alternator efficiency & Cooling fraction & \\
\cline { 2 - 3 } & Expander & Compressor & & & \\
\hline Aero-derivative & $0.87 / 0.80^{\mathrm{a}}$ & 0.88 & 0.99 & 0.98 & 0.996 & 0.122 \\
Medium size & 0.87 & 0.90 & 0.98 & 0.985 & 0.089 & 275 \\
Large size & 0.90 & 0.90 & 0.992 & 0.187 & 921 \\
\hline
\end{tabular}

${ }^{\text {a }}$ For the high pressure and low-pressure expander sections, respectively.

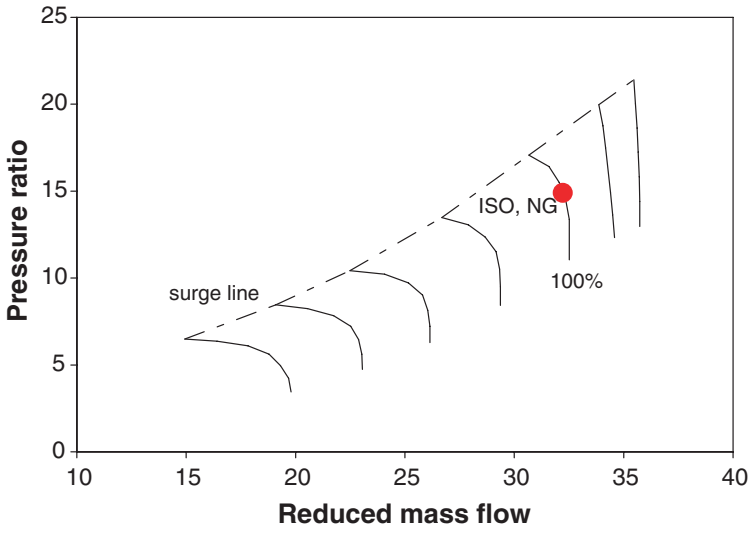

Fig. 2. Typical gas turbine compressor map.

aero-derivative turbine, the maximum compressor pressure ratio for continuous operation is taken from Ref. [18] as 19.3, which corresponds to the case of a LM2500 with an expander of enlarged area. When operating for power generation, aero-derivative engines have a more critical compressor operation and control since the compressor shaft is not connected to a generator and, therefore, spins freely $[3,7]$. This may lead to over speed of the gas generator, which is another limit for the off design operation of an aero derivative engines.

Other relevant assumptions for the thermodynamic simulation of gas turbines are briefly described below. The main assumptions for the power cycle modelling are presented in Table 9.
The equations used within the gas turbine modelling are similar to those presented elsewhere [35-37]. The system of equations for off design gas turbine modelling is defined by Eqs. (1) and (2) and by the set of equations that correspond to the energy conversion modelling inside the compressor, the combustion chamber and the expander.

Basically, compressor and expander equations are defined for polytropic processes of known efficiency, allowing the evaluation of gas outlet temperature and the powers involved with the compression and expansion processes. Because of the changes in pressure ratio, the corrections for the isentropic efficiencies for the compressor and the expander assume constant polytropic efficiency for both devices [8]. The temperatures of the air and gas at the outlet of these devices are then recalculated.

The maximum gas temperature is either evaluated as a function of the known turbine inlet temperature or as the specified de-rated temperature to accomplish surge control. Dissociation of combustion gases is not considered within the calculations. In atmospheric BIGCC cycles, the BDG is supposed to be preheated after the cleanup process, helping combustion stability.

\section{Simulation results}

Calculations were performed for the cycles for each of the three gas turbine control strategies considered. Overall thermal efficiencies are presented on the lower heating value basis and include the gasification conversion effi-

Table 9

Main assumptions adopted for calculations for all simulated cases

\begin{tabular}{ll}
\hline HRSG \& steam cycle & - Approach $\Delta T=30{ }^{\circ} \mathrm{C}$; pinch point $\Delta T=15^{\circ} \mathrm{C}$ \\
& - Heat losses $0.7 \%$ of heat released by gas; pressure drop at the gas side $3 \mathrm{kPa}$, pressure drop at the superheater $10 \%$ \\
- Overall isentropic efficiency of steam turbine 0.75 \\
- Steam pressure at the condenser $9.6 \mathrm{kPa}$ \\
- Water outflow from deaerator: $488 \mathrm{kPa}, 120{ }^{\circ} \mathrm{C}$ \\
- Total auxiliary power $=160 \%$ of the estimated power for the pumps (isentropic efficiency 0.65 ) \\
- Cycle based on aero-derivative $\mathrm{GT}$ : steam raised at $8 \mathrm{MPa}, 480{ }^{\circ} \mathrm{C}$ at the reference case \\
- Medium and large cycles: steam raised at $10 \mathrm{MPa}, 538{ }^{\circ} \mathrm{C}$ at the reference case \\
- Outlet BDG temperature $870{ }^{\circ} \mathrm{C}$, outlet pressure $0.20 \mathrm{MPa}, \Delta p=0.02 \mathrm{MPa}$ \\
- Biomass dried from $50 \%$ to $15 \%$ moisture content, exiting at $70{ }^{\circ} \mathrm{C}$ \\
Dryifier & - $\Delta p / p 2 \%$; heat losses equivalent to $2 \%$ of heat transferred \\
Heat exchangers & - Mechanic and electric efficiencies $90 \%$ \\
BDG compressor & - Polytropic efficiency $80 \%$ \\
Air compressor & $15{ }^{\circ} \mathrm{C}, p=0.1013 \mathrm{MPa}$; humidity $60 \%$ \\
Ambient air &
\end{tabular}

${ }^{\text {a }}$ Steam temperature varies according to the strategy used to burn BDG in gas turbines. 
Table 10

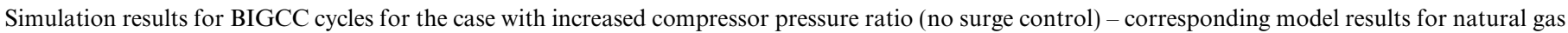
in parenthesis

\begin{tabular}{|c|c|c|c|c|c|c|c|}
\hline Gas turbine & $\begin{array}{l}\text { Net power } \\
(\mathrm{MW})\end{array}$ & $\begin{array}{l}\text { Thermal } \\
\text { efficiency }(\%)\end{array}$ & $\begin{array}{l}\text { GT power } \\
(\mathrm{MW})\end{array}$ & $\begin{array}{l}\text { Steam cycle } \\
\text { power }(\mathrm{MW})\end{array}$ & $\begin{array}{l}\text { Compressor } \\
\text { pressure ratio }\end{array}$ & $\begin{array}{l}\text { Fuel heat input } \\
\text { (MW) }\end{array}$ & $\begin{array}{l}\text { BDG compressor } \\
(\mathrm{MW})\end{array}$ \\
\hline Aero-derivative $^{a}$ & $34.0(29)$ & $39.0(45)$ & $31.0(21.5)$ & $12(8.0)$ & $21(17.5)$ & $76.4(65)$ & 7.4 \\
\hline Medium size & $105.0(94)$ & $41.0(46)$ & $93.0(67.0)$ & $38(28.0)$ & 17 (14.9) & $224.6(203)$ & 20.0 \\
\hline Large size & $235.4(206)$ & $43.2(49)$ & $210.4(153.0)$ & $80(53.4)$ & 17 (14.8) & $476.0(408)$ & 42.3 \\
\hline
\end{tabular}

${ }^{\text {a }}$ Results for natural gas correspond to the case of expander with enlarged area.

Table 11

Simulation results for BIGCC cycles for de-rating the gas turbine

\begin{tabular}{|c|c|c|c|c|c|c|c|}
\hline Gas turbine & $\begin{array}{l}\text { Net power } \\
(\mathrm{MW})\end{array}$ & $\begin{array}{l}\text { Thermal } \\
\text { efficiency }(\%)\end{array}$ & $\begin{array}{l}\text { GT power } \\
\text { (MW) }\end{array}$ & $\begin{array}{l}\text { Steam cycle } \\
\text { power }(\mathrm{MW})\end{array}$ & $\begin{array}{l}\text { Compressor } \\
\text { pressure ratio }\end{array}$ & $\begin{array}{l}\text { Fuel heat input } \\
\text { (MW) }\end{array}$ & $\begin{array}{l}\text { BDG compressor } \\
\text { (MW) }\end{array}$ \\
\hline Aero-derivative & 24.0 & 36.0 & 22.7 & 8.5 & 19.3 & 58.9 & 5.6 \\
\hline Medium size & 87.0 & 39.0 & 77.5 & 31.7 & 16.3 & 196.2 & 17.0 \\
\hline Large size & 194.0 & 41.3 & 176.0 & 65.0 & 16.2 & 391 & 36.0 \\
\hline
\end{tabular}

ciency. The effects of each strategy on the cycle performance are investigated below.

\subsection{Increasing the compressor pressure ratio}

In fact, increasing the compressor pressure ratio is not a strategy to allow the use of BDG, but in terms of machine performance, it is a good basis of comparison since no limits are imposed on the gas turbine operation. The limit for the surge line has been breached for both industrial gas turbines considered, indicating that the increase in pressure ratio to accommodate BDG cannot be handled by either of the two industrial gas turbines. On the other hand, due to the enlarged area of the expander, the surge limit was not breached for the LM2500. Within the simulation, in order to keep the exhaust gases at the minimum drying design conditions $\left(200^{\circ} \mathrm{C}\right)$, the steam generation rate had to be controlled. The simulation results of BIGCC cycles for this case are presented in Table 10 along with results of equivalent cycles operating with natural gas (in parenthesis). With increased mass flow going through the expander, a considerable increase in power production for both the gas turbine and the steam power cycle is achieved visà-vis the corresponding configuration using natural gas. The increments in power production more than compensate for the power requirements for the BDG compressor, so the net power production is higher than that of the natural gas case. Although a higher efficiency for the gas turbine is achieved with BDG, the overall efficiency of the system is lower. The reason for that is that there is a considerable power demand to drive auxiliaries (e.g. the BDG compressor) and the losses associated with the conversion of biomass into $\mathrm{BDG}^{3}$

\footnotetext{
${ }^{3}$ Assumed cold gas efficiency of the atmospheric gasifier was $78 \%$ based on biomass HHV such as in [3].
}

\subsection{De-rating}

As previously mentioned, this surge control strategy leads to a reduction of the gas turbine output power by imposing a lower burning temperature. Yet, comparing with the results of natural gas firing only, some slight increase in gas turbine power is observed due to the larger mass flow. Gas turbine de-rating also impacts the performance of the bottoming steam cycle as the amount of steam raised and its temperatures are reduced. Table 11 presents the simulation results obtained when de-rating is the strategy.

\subsection{Compressor air bleeding}

Bleeding air from the compressor is a more suitable strategy for a BIGCC configuration with pressurized gasification, as the high pressure air can be used for the gasifier. For the case with atmospheric gasification, the extraction of air represents a loss of power if there is no utilization for the compressed air energy. In fact, the air bled from the compressor could be used to generate more power in another expander, but this option was not considered for this evaluation. In this paper, compressor bleeding was imposed for each gas turbine up to the level at which the compressor pressure ratio reaches the estimated maximum value for the gas turbine continuous operation.

The simulation results show that the net power production for BDG only is about the same as when natural gas is considered. Even though there are gains in power production for both gas turbine and steam cycle, they are offset by the compressor power requirements. Comparing to the derating case, there are considerable gains in power (around $20 \%$ ) but marginal gains in thermal efficiency. Some simple retrofit might be necessary for this case with additional investments. The simulation results for this surge control strategy are presented in Table 12. 
Table 12

Simulation results for BIGCC cycles considering compressor air bleeding (compressor pressure ratio the same as in Table 11)

\begin{tabular}{lllllcrr}
\hline Gas turbine & $\begin{array}{l}\text { Net power } \\
(\mathrm{MW})\end{array}$ & $\begin{array}{l}\text { Thermal } \\
\text { efficiency }(\%)\end{array}$ & $\begin{array}{l}\text { GT power } \\
(\mathrm{MW})\end{array}$ & $\begin{array}{l}\text { Steam cycle power } \\
(\mathrm{MW})\end{array}$ & $\begin{array}{l}\text { Fuel heat input } \\
(\mathrm{MW})\end{array}$ & $\begin{array}{l}\text { Bleed air } \\
(\mathrm{kg} / \mathrm{s})\end{array}$ & $\begin{array}{l}\text { Syngas compressor } \\
(\mathrm{MW})\end{array}$ \\
\hline Aero-derivative & 29.0 & 37.0 & 24.0 & 11.4 & 68.7 & 5.6 & 6.5 \\
Medium size & 97.8 & 39.8 & 83.7 & 37.4 & 216.3 & 13.0 & 19.0 \\
Large size & 217.0 & 42.0 & 189.0 & 77.3 & 457.4 & 27.0 & 40.0 \\
\hline
\end{tabular}

\subsection{Retrofitting the expander}

Retrofitting the gas turbine expander presumes changes in expander geometry so that it can cope with the larger gas flow that goes through the gas turbine and yet maintain the compressor pressure ratio at the design values. The results that correspond to this strategy have been estimated by increasing the critical area $A^{*}$ in Eq. (1), which can be practically achieved by increasing the high pressure turbine blade height or nozzle discharge angle [3]. For each gas turbine, the new critical area was estimated as the one that allows compressor operation at the nominal (ISO) pressure ratio. Gas turbine temperatures were also supposed to reach their maximum in each case. Generally, the results for thermal efficiency are about the same as the case that corresponds to accepting a larger pressure ratio. On the other hand, better results regarding power are obtained. Table 13 presents the simulation results obtained in this work.

\subsection{Comparison of results}

A comparison among the simulation results for the three modelled cycles is performed in Figs. 3 and 4. The results in Fig. 4 are presented as a proportion of the hypothetical case in which there is no control for the rise of compressor pressure ratio.

Retrofitting the gas turbine expander is clearly the best strategy from the point of view of both power production and plant thermal efficiency, leading to results even better than the case that accepts the increase of compressor pressure ratio. For instance, when the strategy based on enlarged expander area is applied, the gains with output power can be as high as $8 \%$. Conversely, gas turbine de-rating is the worst strategy, especially from the point of view of power production. For the aero-derivative case, for example, the net power produced is only $70 \%$ of the power produced with no surge control. Compressor bleed presents results slightly better than the strategy based on de-rating.

Table 13

Simulation results for BIGCC cycles considering retrofitting the gas expander (compressor pressure ratio as in design case)

\begin{tabular}{|c|c|c|c|c|c|c|c|}
\hline Gas turbine & $\begin{array}{l}\text { Net power } \\
\text { (MW) }\end{array}$ & $\begin{array}{l}\text { Thermal } \\
\text { efficiency (\%) }\end{array}$ & $\begin{array}{l}\text { GT power } \\
\text { (MW) }\end{array}$ & $\begin{array}{l}\text { Steam cycle power } \\
\text { (MW) }\end{array}$ & $\begin{array}{l}\text { Fuel heat input } \\
\text { (MW) }\end{array}$ & $\begin{array}{l}\text { Increase in } \\
A^{*}(\%)\end{array}$ & $\begin{array}{l}\text { BDG compressor } \\
\text { (MW) }\end{array}$ \\
\hline Aero-derivative & 35.0 & 40.0 & 31.0 & 12.6 & 76.0 & 22 & 7.2 \\
\hline Medium size & 113.3 & 41.3 & 97.2 & 42.6 & 242.7 & 22 & 20.1 \\
\hline Large size & 251.0 & 43.4 & 219.0 & 88.0 & 506.0 & 21 & 42.0 \\
\hline
\end{tabular}

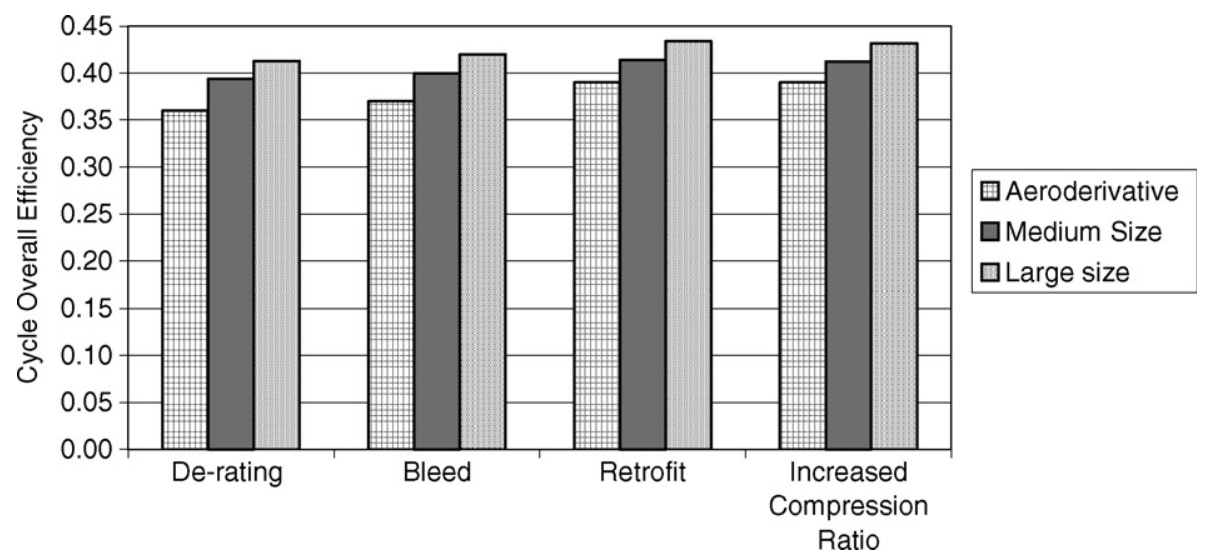

Fig. 3. Results on thermal efficiency for different gas turbine control strategies in comparison to the case with no surge control strategy. 


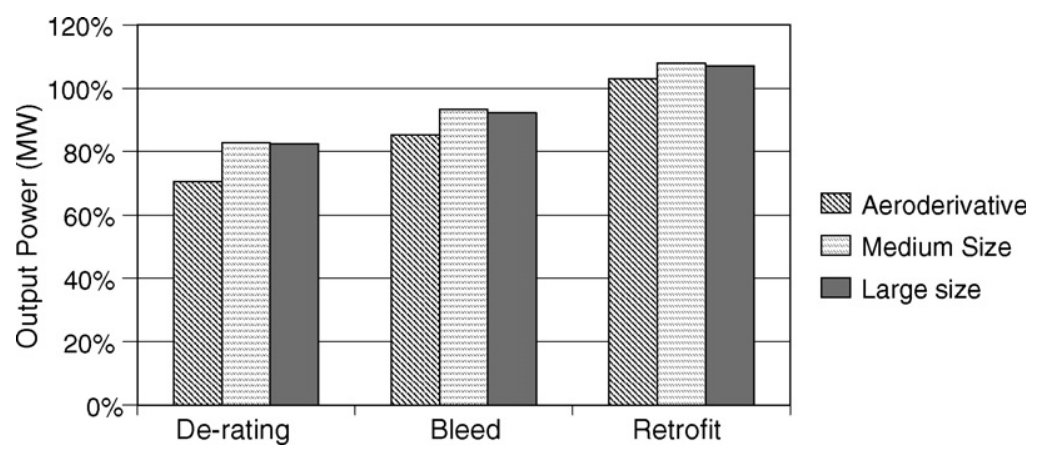

Fig. 4. Results on power production for different gas turbine control strategies in comparison to the case with no surge control strategy.

The worst simulation results with respect to performance were obtained for the power plant based on the aero-derivative gas turbine. This result stems from the assumption of a smaller variation of compressor pressure ratio. As the same variation was assumed for the simulation of industrial gas turbines (results identified as medium and large sizes), performance penalties are comparable. Comparing the aero-derivative turbine with industrial gas turbines, the performance differences are clear for the derating strategy, with small difference using bleed and even negligible when retrofit is applied. The reason is that within the simulation, to achieve the imposed limit on pressure ratio, it was necessary to reduce the maximum temperature in the aero-derivative case (down to $90 \%$ of its maximum) vis-à-vis the reduction in the industrial cases (down to $93 \%$ ).

Gains regarding thermal efficiency of the bleed option compared to de-rating could be as high as $6 \%$ for the aero-derivative case if there were no lower limit for the HRSG exhaust gas temperature. Because of the drying design constraint that is related to the minimum temperature required for the dryer, ${ }^{4}$ the thermal efficiency is only $3 \%$ higher. This is also the reason why the gains with enlargement of the gas turbine expander critical area for the efficiency were only marginal.

\section{Conclusions}

This work aimed at a performance evaluation of atmospheric BIGCC cycles of different capacities fuelled by sugar cane derived gases. Regarding the suitability of sugar cane derived gas for use in gas turbines, most of the issues related to the physical and chemical properties of sugar cane bagasse and trash seem to be possible to overcome. Gas cleanup systems should be effective to fulfil the strict requirements of gas turbines regarding particulate, alkali and tars.

From the point of view of power plant performance, strong penalties are predicted due to the strategies of surge control imposed on gas turbines. As a result of stricter

\footnotetext{
${ }^{4}$ This temperature is higher than the acid dew point in which condensation of dilute sulphuric acid occurs.
}

surge control, stronger penalties are expected for power plants based on aero-derivative gas turbines rather than those based on heavy industrial machines. This stricter control is necessary to avoid over speed, taking into account that the gas generator, unlike the power turbine, spins freely.

For all the modelled cycles, it is clear that gas turbine de-rating is the worst strategy for the use of LCV fuels, despite the fact it could be used in the short term. When de-rating is applied, the thermal efficiency of BIGCC cycles can be lowered to $92 \%$ of the value of the case with increased pressure ratio (no surge control on the gas turbine compressor) or to $80 \%$ of the efficiency value on natural gas. Even higher losses are observed for the output power, as gas turbine de-rating can result in a 30\% power reduction at the worst case (aero-derivative case) and by $20 \%$ at the best, both in relation to the case with no surge control.

Conversely, redesign of the gas turbine expander is clearly the best strategy and would be used as long as the market for BIGCC technology gets developed. As typical current gas turbine constraints are reduced, power cycles can take full advantage of a larger mass flow. The results for this option could be even better if no constraint is imposed on minimum HRSG exhaust temperature.

\section{Acknowledgements}

Monica Rodrigues Souza is grateful to the Brazilian agencies $\mathrm{CNPq}$ and CAPES for the financial support received during her work at the University of Campinas, Brazil, and Utrecht University, The Netherlands. This paper also reports results of research developed with the financial support of Fundação do Amparo a Pesquisa do Estado de São Paulo - FAPESP (project 2001/14302-1). The authors would like to thank Eileen and Michael Zimmerman for their help on language editing.

\section{References}

[1] Bauen A, Woods J, Hailes R. Biopowerswitch! London: WWF International and Aebiom; 2004 
[2] Faaij A, Van Ree R, Waldheim L, Olssom E, Oudhuis A, Van Wijk A, et al. Gasification of biomass wastes and residues for electricity production. Biomass Bioenergy 1997;12(4):225-40.

[3] Consonni S, Larson ED. Biomass-gasifier/aeroderivative gas turbine combined cycles. Part A - technologies and performance modelling. J Eng Gas Turbines and Power 1996;118(3):507-15.

[4] Overend R. Biomass gasification: the enabling technology. Renewable energy world 2000, September-October. Available at http:// www.jxj.com.

[5] Waldheim L. Overview of gasification of biomass 2005. Presentation in Piracicaba, Brazil, September 2005. Available at http:// www.ctc.com.br.

[6] Cione M, La Marca C, Riccardi J. RDF gasification in a circulating fluidised bed gasifier: characterization of syngas and ashes. ENEL Produzione S.p.A, Research Department. Available at http://www. icheme.org/literature/conference.

[7] Johnson MS. The effects of gas turbine characteristics on integrated gasification combined-cycle power plant performance. $\mathrm{PhD}$ dissertation, Stanford University; 1990.

[8] Cohen H, Rogers GFC, Saravanamuttoo HIH. Gas turbine theory. fourth ed. London: Wesley Logman Limited; 1996.

[9] Rodrigues M, Walter A, Faaij A. Co-firing of natural gas and biomass gas in biomass integrated gasification/combined cycle systems. Energy 2003;28:1115-31.

[10] Rodrigues M, Faaij A, Walter A. Techno-economic analysis of cofired biomass integrated gasification/combined cycle systems with inclusion of economies of scale. Energy 2003;28:1229-58.

[11] Babu SP. Thermal gasification of biomass technology developments: end of task report for 1992-1994. Biomass Bioenergy 1995;9(1-5):271-85.

[12] Jorapur R, Rajvanshi A. Sugarcane leaf-bagasse gasifiers for industrial heating applications. Biomass Bioenergy 1997;13(3):141-6.

[13] Copersucar Technology Center. Project BRA/96/G31 - Energy generation from biomass, sugar-cane bagasse and residues, Piracicaba: CTC; 1998 [in Portuguese].

[14] Palmer CA, Erbes MR, Pechtl PA. Gate cycle performance analysis of the LM2500 gas turbine utilizing low heating values. IGTI ASME Cogen-Turbo; 1993.

[15] Walter A, Souza M, Faaij A. Feasibility of co-firing biomass + natural gas systems. In: Fourth biomass conference of the Americas; 1999.

[16] GEF/Copersucar Project. Analytical results for sugar leaves and tops with and without vinasse. International cane energy network annual meeting; 1997.

[17] Waldheim L, Morris M, Leal MRLV. Biomass power generation: sugar cane bagasse and trash. Progress in thermo-chemical biomass conversion; 2000.

[18] Consonni S, Larson ED. Biomass-gasifier/aeroderivative gas turbine combined cycles. Part B - performance calculations and economic assessment. $\mathbf{J}$ Eng Gas Turbines Power 1996;118(3):516-25.

[19] Kloster R, Oeljekaus G, Pruschek R. In: Schmidt E, editor. High temperature gas cleaning. TH Karlsruhe, Karlsruhe; 1996.

[20] Salo K, Mojtahedi W. Fate of alkali and trace metals in biomass gasification. Biomass Bionergy 1998;15(13):263-7.

[21] Jekins BM, Bakker RR, Wei JB. On the properties of washed straw. Biomass Bioenergy 1996;10(4):177-200.

[22] Zhou J, Kinoshita CM, Wang Y. Simulation of fuel-bound nitrogen evolution in biomass gasification. In: 32nd Intersociety energy conversion engineering conference; 1997.

[23] Lietti L, Ramella C, Groppi G, Forzatti P. Oxidation of $\mathrm{NH}_{3}$ and $\mathrm{NO}_{x}$ formation during the catalytic combustion of gasified biomass fuels over Mn-hexaaluminate and alumina-supported Pd catalysts. Appl Catal B: Environ 1999;21(2):89-101.

[24] Cook CS, Corman JC, Todd DM. System evaluation and LBTU fuel combustion studies for IGCC power generation. J Eng Gas Turbines Power 1995;117(4):673-7.

[25] Hoppesteyn PDJ. Application of low calorific value gaseous fuels in gas turbine combustors. $\mathrm{PhD}$ dissertation. Technical University of Delft; 1999.

[26] Neilson CE. LM2500 gas turbine modifications for biomass fuel operation. Biomass Bioenergy 1998;15(3):269-73.

[27] De Kant HF, Bodegom M. Study on applying gasifiers for co-firing natural gas fired energy conversion facilities. Utrecht; November 2000 [in Dutch].

[28] Stambler I. Repower steel mills with combined cycles to increase output and cut $\mathrm{NO}_{x}$. Gas Turbine World 1999;29(3):26-30.

[29] Walter A, Llagostera J, Gallo W. Impact of gas turbine de-rating on the performance and on the economics of BIG-GT cycles. ASME international mechanical engineering congress and exposition; 1998.

[30] Anand AK, Cook CS, Corman JS, Smith AR. New technology trends for improved IGCC system performance. J Eng Gas Turbines Power 1996;118(4):732-6.

[31] Llagostera J, Walter A. Off-design operation of co-fired combined cycles. In: 16th international conference on efficiency, cost, optimization, simulation and environmental impact of energy systems; 2003, 3: $1443-50$.

[32] Kapat JS, Agrawal AK, Yang T. Air extraction in a gas turbine for integrated gasification combined cycle (IGCC): experiments and analysis. J Eng Gas Turbines Power 1997;119(1):20-6.

[33] Corman JC, Todd DM. Technology considerations for optimizing IGCC plant performance. ASME international gas turbine and aero engine congress and exposition; 1993.

[35] Gas Turbine World 1999-2000 handbook. Pequot Publishing; 2000.

[36] Bathie WW. Fundamentals of gas turbines. New York: John Wiley \& Sons; 1996.

[37] El Hadik AA. The impact of atmospheric conditions on gas turbine performance. J Eng Gas Turbines Power 1990;112:590-6. 